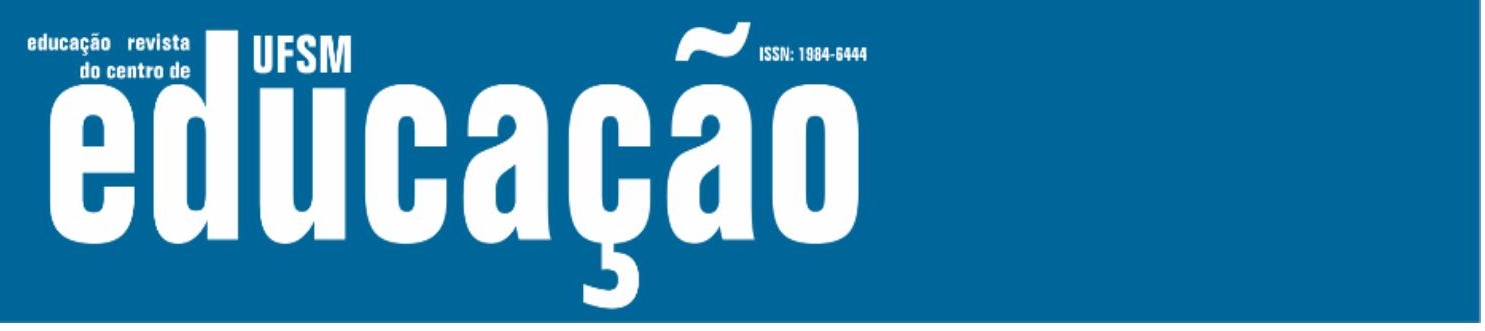

ISSN: 1984-6444 | http://dx.doi.org/10.5902/1984644447075

\title{
A formação do educador no âmbito da educação não formal
}

\section{Educator training in the contexto of non-formal education}

Marleide Rodrigues da Silva Perrude

Professora Doutora na Universidade Estadual de Londrina, Londrina, Paraná, Brasil.

marleideperrude@gmail.com - https://orcid.org/0000-0002-5855-5231

Ana Lucia Ferreira Silva

Professora Doutora na Universidade Estadual de Londrina, Londrina, Paraná, Brasil.

a.ferreira@uel.br - https://orcid.org/0000-0001-7602-2810

Recebido em 10 de junho de 2020

Aprovado em 15 de abril de 2021

Publicado em 27 de janeiro de 2022

\section{RESUMO}

Este trabalho tem como foco discutir a formação do educador que atua em espaços de educação não formal. Por meio de um estudo teórico, tem-se como objetivo analisar aspectos relativos à formação do educador que atua nestes espaços, além de problematizar sua atuação no que respeita a suas ações e práticas pedagógicas. O estudo parte da seguinte indagação: quais princípios devem nortear as ações de educadores que atuam no âmbito da educação não formal? O estudo é ancorado em pesquisa bibliográfica e análise qualitativa. A pesquisa revela que a formação do educador para atuar em espaços não formais não se dá de forma espontânea e nem apenas no âmbito teórico ou no âmbito da prática. Esta formação deve ter como elemento norteador o compromisso tanto de quem oferece a formação, quanto do sujeito/educador, sendo, portanto, uma via de mão dupla. A formação do educador se faz na práxis. Conclui-se, destacando a necessidade de pensar a formação e a atuação do educador, fundamentada na capacidade de comprometer-se com o trabalho na constante interação com o contexto em que sua ação educativa é desenvolvida.

Palavras-chave: Educação não formal; Formação do Educador; Práxis.

\section{ABSTRACT}

This work focuses on discussing the formation of the educator who works in non-formal education spaces. Through a theoretical study, the objective is to analyze aspects related to the education of the educator who works in these spaces, in addition to problematizing his performance with regard to his pedagogical actions and practices. 


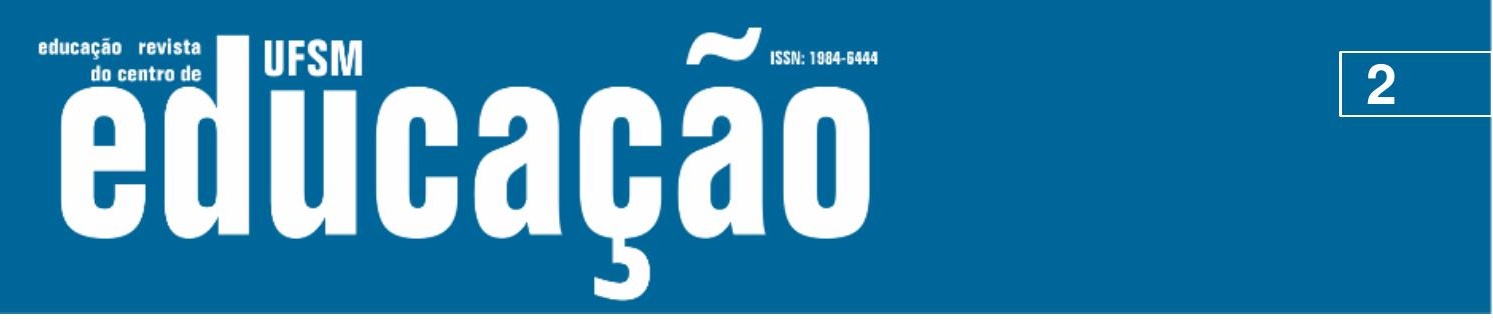

ISSN: 1984-6444 | http://dx.doi.org/10.5902/1984644447075

The study starts from the following question: what principles should guide the actions of educators working in the context of non-formal education?

The research reveals that the education of the educator to work in non-formal spaces does not happen spontaneously and not only in the theoretical or practical scope. This training should have as a guiding element the commitment of both the person providing the training and the subject / educator, being, therefore, a two-way street.

The educator's training takes place in praxis. It concludes, highlighting the need to think about the educator's training and performance, based on the ability to commit to work in constant interaction with the context in which their educational action is developed.

Keywords: Non-formal education; Educator Training; Praxis.

\section{Introdução}

Este trabalho se propõe discutir a formação do educador no desenvolvimento de ações pedagógicas realizadas no âmbito da educação não formal e situar, neste contexto, alguns aspectos relativos ao trabalho com crianças e adolescentes nestes espaços. Por educação não formal, estabelecemos, para melhor compreensão da temática proposta, ações desenvolvidas a partir de uma intencionalidade educativa, as quais não correspondem às estabelecidas pelo processo de escolarização formal, que ocorrem nos estabelecimentos de ensino tradicionais e oficiais - as escolas - e demais instituições de ensino que apresentem caráter formal, regidas por instituições superiores, certificadoras de titularidades e por uma legislação nacional que normatiza critérios e procedimentos de ensino e avaliação. Conforme Gohn (2016), a educação não formal é regida sob outro enfoque, o qual toma como prioritárias as categorias espaço e tempo, pelo fato, em especial, de a educação não formal não apresentar um currículo com conteúdo e temas definidos a priori.

O estudo remete à necessidade de situar a conjuntura em que os sujeitos educador e educando - estão inseridos e são formados. Os apontamentos apresentados partem de nossas experiências com estágios supervisionados, em gestão da educação não formal no curso de Pedagogia, em uma instituição de ensino superior pública, em cursos e oficinas ministrados para educadores que atuam nestes espaços no município em que trabalhamos. Ampara-se a presente pesquisa em 


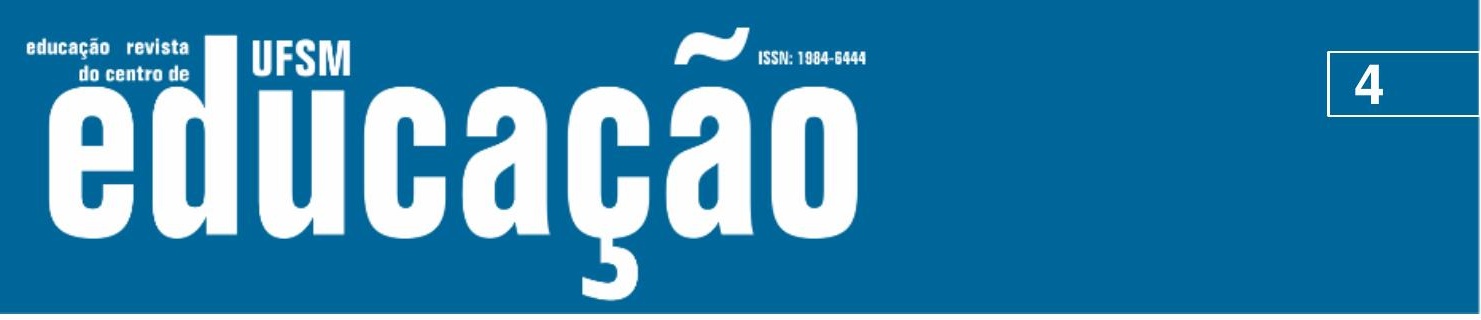

ISSN: 1984-6444 | http://dx.doi.org/10.5902/1984644447075

Ao mesmo tempo, observa-se que algumas políticas de governo, denominadas compensatórias e, portanto, emergenciais, têm tido visibilidade e permanência, e recebido status de política pública. Ainda de acordo com Frigotto (2010), no contexto da atual crise, o "[...] capital está expondo limites nunca antes expostos com igual magnitude e intensidade, resultado de sua forma contraditória e, por isso, destruindo, de forma devastadora, direitos constituídos ao longo, especialmente, dos últimos 100 anos" (FRIGOTTO, 2010, p. 419).

Neste contexto social e político brasileiro, é que situamos a educação não formal. Este campo, ainda em construção, conforme análises de Gohn (2016), objetiva atividades de natureza educativa que extrapolam ações tidas como escolarizantes, uma vez que o campo formal, historicamente, se constituiu e alcançou mérito e reconhecimento na sociedade brasileira. A educação não formal, conforme dito, se encontra em construção e, portanto, sua validade e reconhecimento também se encontram em desenvolvimento, em processo. Se no campo das políticas públicas o campo não formal ainda está longe de receber a devida atenção e, se no âmbito da sociedade em geral este campo não tem encontrado o devido reconhecimento, é no próprio campo - não formal - que saltos qualitativos vêm sendo percebidos, impulsionando, assim, a necessidade de estudos e pesquisas que visem à construção de novos referenciais e aprofundamento teórico-metodológico, visto que, na prática, o trabalho nos espaços de educação não formal vêm sendo desenvolvidos e exigidos, cada vez mais, dos sujeitos que neles atuam embasamento e aprofundamento teórico para o desenvolvimento de suas práticas. Diante do exposto, este trabalho tem como foco discutir aspectos relativos à formação do educador que atua em espaços de educação não formal. Considerando a diversidade de ações e práticas que constituem o universo ao qual se faz referência, propõe-se discutir a formação de educadores que atuam com crianças e adolescentes no âmbito socioassistencial, partindo o estudo da seguinte indagação: Quais princípios devem nortear as ações de educadores que atuam no âmbito da educação não formal? O estudo se justifica tendo em vista o crescente espaço que vem sendo ocupado por ações no campo da educação não formal, em especial, o trabalho realizado junto a crianças e adolescentes em situação de vulnerabilidade social. Assevera-se que o trabalho voltado a sujeitos e grupos 


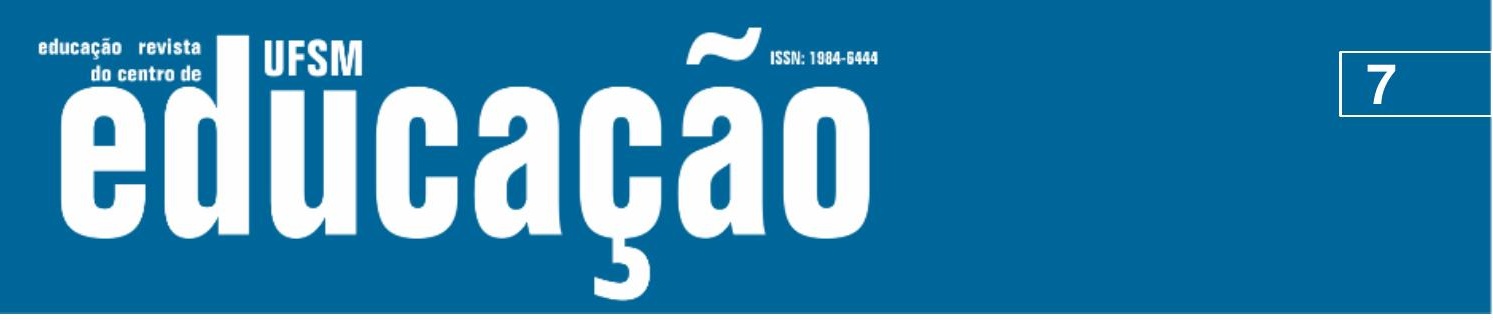

ISSN: 1984-6444 | http://dx.doi.org/10.5902/1984644447075

[...] designa um processo com várias dimensões, tais como: a aprendizagem política dos direitos dos indivíduos enquanto cidadãos; a capacitação dos indivíduos para o trabalho, por meio da aprendizagem de habilidades e/ou desenvolvimento de potencialidades; a aprendizagem e exercício de práticas que capacitam os indivíduos a se organizarem com objetivos comunitários, voltadas para a solução de problemas coletivos cotidianos; a aprendizagem de conteúdos que possibilitem que os indivíduos façam uma leitura do mundo do ponto de vista de compreensão do que se passa ao seu redor; a educação desenvolvida na mídia e pela mídia, em especial a eletrônica etc.

A educação não formal, segundo Gohn (2016), ultrapassa a aprendizagem de conteúdos relativos aos da escolarização, tendo em vista que busca fornecer elementos formativos que possam propiciar aos sujeitos uma leitura mais aproximada da realidade que os cerca. Gohn (2020, p. 12) irá aprofundar esta definição de educação não formal quando a situa enquanto:

[...] um processo sociopolítico, cultural e pedagógico de formação para a cidadania, entendendo o político como a formação do indivíduo para interagir com o outro em sociedade. Ela designa um conjunto de práticas socioculturais de aprendizagem e produção de saberes, que envolve organizações/instituições, atividades, meios e formas variadas, assim como uma multiplicidade de programas e projetos sociais.

Os saberes produzidos nesse campo se estendem e têm como principal foco a formação para a cidadania. Destaca-se que a formação política é um elemento chave para se pensar as ações no campo da educação não formal. Falar do campo não formal exige, portanto, a necessidade de situarmos quem são os sujeitos que compõem este campo, para quem a possibilidade de experienciar um novo processo formativo é direcionado. Sujeitos que frequentam tais espaços carregam as marcas da exclusão, visto pertencerem a uma determinada classe: a classe trabalhadora, caracterizada como: 


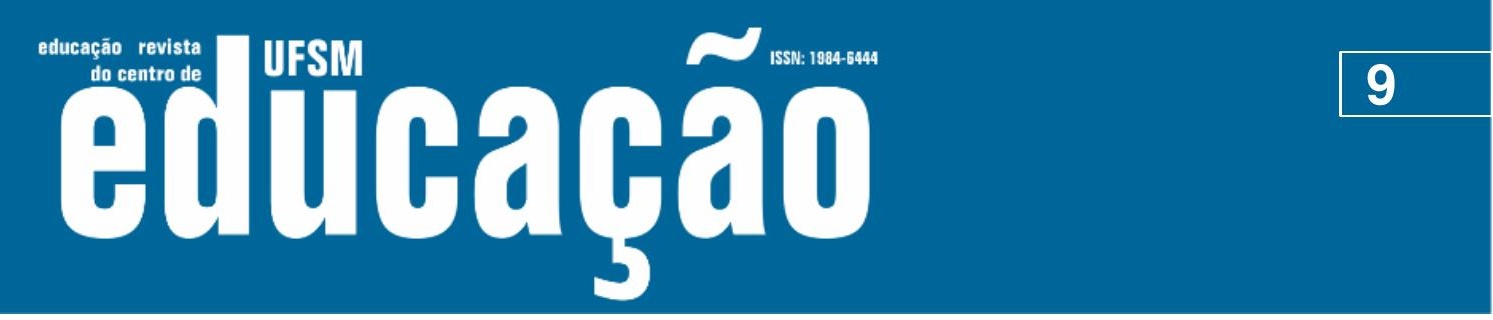

ISSN: 1984-6444 | http://dx.doi.org/10.5902/1984644447075

setor público e as entidades que desenvolvem suas propostas para o segmento criança e adolescente, em parceria com o setor público, cuja finalidade seja a proteção e a garantia de direitos, devem seguir as normas e orientações para os serviços socioassistenciais, que são preconizados pelo Sistema Único de Assistência Social (SUAS). De acordo com o documento Tipificação Nacional dos Serviços Socioassistenciais (2009) e a Política Nacional de Assistência Social (2004), estes serviços são organizados por níveis de proteção e complexidade, a saber: Proteção social básica e Proteção social especial - média e alta complexidade.

A temática referente às ações socioeducativas tem auferido espaço em políticas, programas e projetos de governo. Tais ações, vinculadas a conceitos como inclusão, promoção social e protagonismo, estão relacionadas ao âmbito da Assistência Social ${ }^{1}$ e à Política Nacional da Assistência Social em vigor, instâncias que ressaltam a necessidade da oferta de ações socioeducativas. Para Schmidt e Silva (2015, p. 87), "A partir dos anos 2000, a Política de Assistência Social assumiu papel central nas estratégias governamentais" e objetiva articular as ações educativas e atendimentos socioassistenciais de acordo com a Lei Orgânica da Assistência Social (LOAS, 1993), que prevê ações socioeducativas destinadas a crianças e adolescentes, na faixa etária de 6 a 17 anos, visando à proteção, socialização e o fortalecimento de vínculos familiares e comunitários.

Os debates em torno dos projetos sociais que desenvolvem atividades no âmbito da educação não formal, direcionadas a crianças e adolescentes, vêm sendo fortalecidos com o intuito de romper as velhas práticas assistenciais ou solidárias que outrora perpassavam as ações direcionadas para estes sujeitos. Algumas especificidades sobre 0 trabalho pedagógico nesses espaços vêm sendo reconhecidas e seus debates aprofundados, conforme indicado por Perrude e Silva (2013), tais como: a intencionalidade educativa; necessidade de uma proposta pedagógica; objetivos pedagógicos explicitamente definidos e $\circ$ trabalho sendo desenvolvido por profissionais com formação adequada.

Dentre os avanços nesse campo, faz-se necessário ressaltar a legislação vigente, a qual tem impulsionado políticas e propostas no âmbito da educação não formal, dentre os quais, destacam-se a Constituição Federal de 1988 (BRASIL, 1988) 


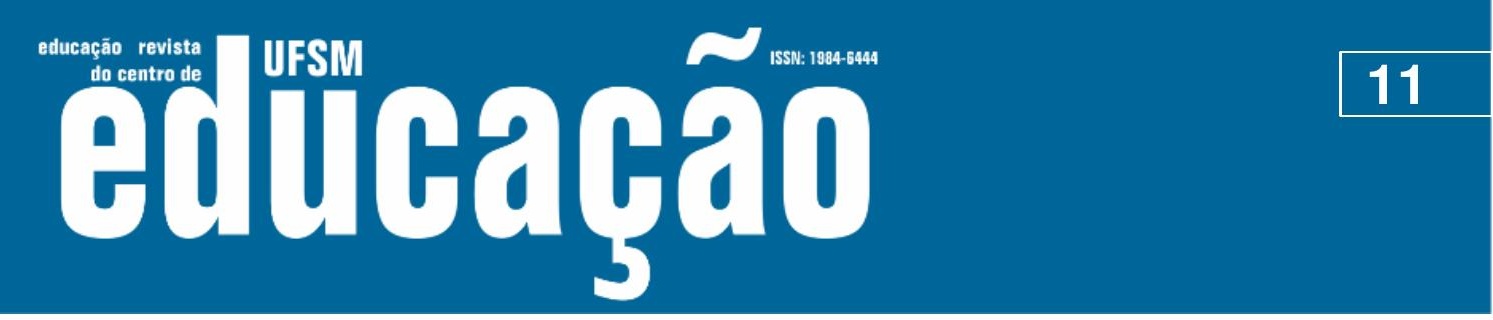

ISSN: 1984-6444 | http://dx.doi.org/10.5902/1984644447075

\section{Princípios teórico-metodológicos norteadores da prática do educador}

Ao destacar a formação de educadores para atuar em espaços de educação não formal, Gohn (2009) postula que são evidentes a carência na formação do educador que atua nos projetos, a necessidade de sistematização das metodologias pedagógicas, a não continuidade das ações nesses espaços e a dificuldade de apoio às práticas desenvolvidas. Isso porque, talvez, a questão da formação para a educação não formal seja uma realidade nova e desafiadora. Segundo Garcia (2008, p. 10):

[...] não há instituições responsáveis por essa formação específica, sendo que ela se dá majoritariamente na prática em situações e instituições que atuam de diferentes maneiras, tendo a relação educacional como mediadora de projetos e, em geral, uma proposta política de mudança social.

De acordo com a autora, há uma diversidade de profissionais entre os educadores que atuam, em variadas funções em projetos no campo da educação não formal, visto serem de diferentes áreas e possuírem diferentes formações iniciais, tais como pedagogia, assistência social, saúde, psicologia, terapia ocupacional, ciências sociais e outras. Dentre esses profissionais, Garcia (2008) destaca:

[...] professores de música, teatro, dança, artes plásticas, expressão corporal (ao considerarmos os mais usuais), sendo que já há algum tempo outros sujeitos com seus fazeres e saberes vêm adentrando esse campo, tais como skatistas, malabaristas, grafiteiros, artesãos, pagodeiros, rappers, b-boys e b-girls, percussionistas, dançarinos de Axé, contadores de histórias, capoeiristas, entre muitos outros (GARCIA, 2008 p. 11).

Esses novos agentes vêm contribuindo para o andamento e o aperfeiçoamento dessas diferentes propostas, pois é no dia a dia que os educadores têm edificado os referenciais para a realização e construção de um perfil de educador com suas diferentes denominações para atuar nos muitos projetos e instituições que assumem o trabalho nesse campo. 


\section{Tusm ollubarao

ISSN: 1984-6444 | http://dx.doi.org/10.5902/1984644447075

Este profissional, agora denominado apenas como educador ou como educador social ${ }^{4}$, tem a responsabilidade de trabalhar um conjunto de conhecimentos para um grupo de crianças e/ou adolescentes em um contexto institucional. Assim, vão criando um conjunto de saberes que são construídos no enfrentamento das problemáticas cotidianas, nas inúmeras reuniões, nas discussões de casos, nos planejamentos, nas supervisões realizadas pela equipe de coordenação e acompanhamento, nas leituras e cursos de formação.

Considerando a flexibilidade desse campo de atuação e da formação dos sujeitos é que este debate ganha sustentação e gera um conjunto de questionamentos, entre os quais se destacam: Quais princípios devem nortear a prática de educadores que atuam na educação não formal? Quais aspectos relativos à formação do educador deve ser observados para atuar nesse espaço? Quais conhecimentos são necessários? Onde esta formação deve ocorrer? Quem é o responsável por ela?

Este tópico é norteado por uma questão de fundo: como se forma um educador? É comum nos depararmos com afirmações vindas inclusive dos próprios educadores "de que aprendem na prática", atribuindo ao exercício profissional um papel formativo. No entanto, mesmo reconhecendo que a prática cotidiana possibilita a formação, precisamos questionar em que condições esta experiência profissional permite ao educador romper com convicções já instaladas, produzindo mudanças relevantes em sua prática. Precisamos reconhecer que a formação dos educadores e as práticas por eles desenvolvidas não podem ser dissociadas, uma vez que:

[...] A formação não se faz apenas a partir de textos científicos e acadêmicos. A formação ocorre no encontro, no centro das correlações de forças, nos quais os textos ganham novas leituras. A reflexão que brota da convivência, como têm demonstrado as experiências de formação de educadores, deve ser valorizada (NETO, 2012, p. 60).

A formação ocorre na constante interação com o contexto em que o educador desenvolve sua ação educativa, levando em conta suas necessidades de formação mediada com o conjunto de referenciais teóricos e metodológicos. Nessa relação é 


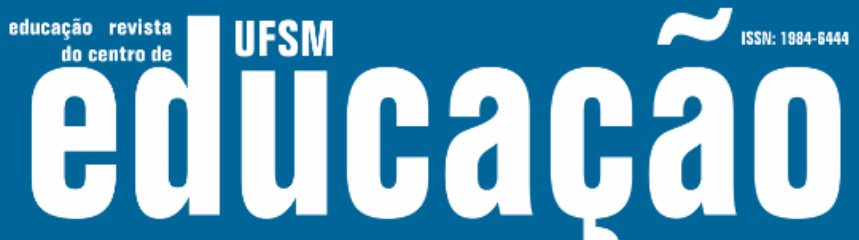

ISSN: 1984-6444 | http://dx.doi.org/10.5902/1984644447075

\section{Considerações finais}

A formação não se dá apenas no âmbito teórico e nem no âmbito da prática. A formação não se dá de forma espontânea. Esta formação deve ser um compromisso de ambas as partes: tanto de quem a oferece (o coordenador, a gerência, a universidade), quanto do sujeito/educador, portanto uma via de mão dupla. Um educador não nasce pronto e acabado, ou seja, ele se faz na práxis.

Sobre o processo de formação de educadores para atuar no campo não formal, alguns esperam que esta formação deva ocorrer em condições ideais. Enfatiza-se, porém, que ela se dá em condições reais, ou seja, não é possível ficar esperando que as condições ideais se materializem, visto que é preciso pensar e enfrentar as condições reais postas e impostas por um conjunto de elementos (entre estes, os de natureza econômica, política, social), os quais irão direcionar políticas e processos, definirão escolhas de quem gerencia o processo, enfim, darão prioridade e conformidade à formação daqueles que se encontram à frente do processo formativo de crianças e dos adolescentes.

Para atuar no espaço de educação não formal, exige-se conhecimento acerca dos sujeitos a quem o serviço é oferecido, ou seja, é preciso reconhecer que o objetivo do trabalho do educador são as crianças e adolescentes, sujeitos de direitos. $O$ trabalho, portanto, deve ser pensado tendo em vista estes sujeitos reais e não sujeitos ideais.

Entender o campo da educação não formal, enquanto espaço de garantia de efetivação de direitos sociais, consequentemente, significa compreender que o processo educativo, que deve ocorrer nesses espaços, não é nenhuma benesse do proponente, nenhum favor, mas, sim, a concretização do que indica a Constituição Federal (CF/88) e o ECA (1990), no sentido da efetivação da garantia de direitos de crianças e adolescentes. 


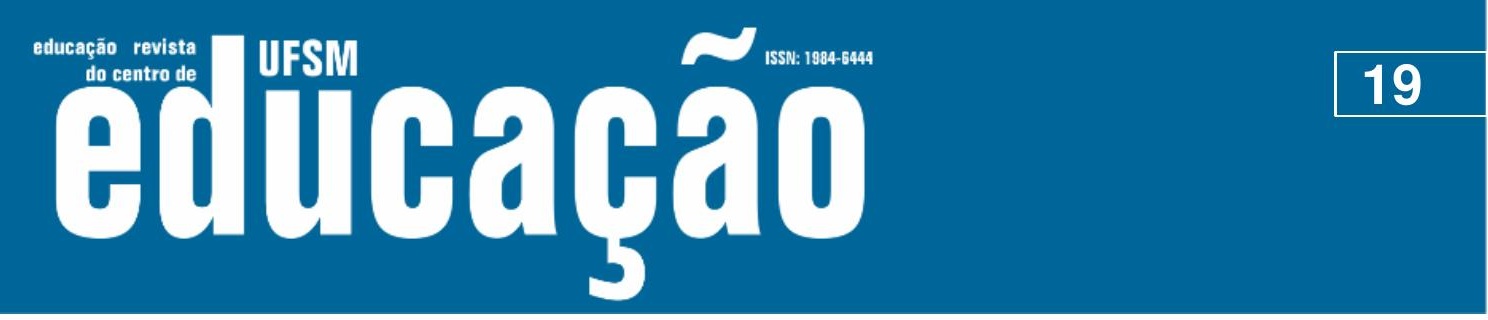

ISSN: 1984-6444 | http://dx.doi.org/10.5902/1984644447075

\section{Referências}

BRASIL. Constituição (1998). Constituição da República Federativa do Brasil de 1988. Brasília, DF. Presidência da República, [2016]. Disponível em http://www.planalto.gov.br/ccivil_03/Constituicao/Constituiçao.htm. Acesso em: 21 de fev. 2020.

BRASIL. Estatuto da Criança e do Adolescente. Lei 8069 de 1990 e suas alterações. Disponível em: http://www.planalto.gov.br/ccivil_03/leis/18069.htm Acesso em: 21 de fev. 2020.

BRASIL. Lei Orgânica da Assistência Social. Lei no 8.742, de 7 de dezembro de 1993. Disponível em http://www.planalto.gov.br/ccivil_03/leis//8742.htm. Acessado em 14/08/2020.

BRASIL. Norma Operacional Básica: NOB-SUAS. 2012.

BRASIL. Norma Operacional Básica de Recursos Humanos: NOB-RH/SUAS: Anotada e comentada. 2011.

BRASIL. Política Nacional de Assistência Social: PNAS/2004. 2005. Reimpresso em 2013.

BRASIL. Tipificação Nacional dos Serviços Socioassistenciais. 2009. Reimpressão 2014.Diponível em: https://www.mds.gov.br/webarquivos/publicacao/assistencia_social/Normativas/tipific acao.pdf. Acessado em 10/08/2020.

DAGNINO, Evelina. "¿Sociedade civil, participação e cidadania: de que estamos falando?" En Daniel Mato (coord.), Políticas de ciudadanía y sociedad civil en tiempos de globalización. Caracas: FACES, Universidad Central de Venezuela, 2004. (p. 95-110).

FREIRE, Paulo. Pedagogia do Oprimido. Rio de Janeiro: Paz e Terra, 2005.

FRIGOTTO, Gaudêncio. Exclusão e/ou Desigualdade Social? Questões teóricas e político-práticas. Cadernos de Educação - FaE/PPGE/UFPel, Pelotas, n. 37, p. 417442, set./dez. 2010.

FUHRMANN, Nadia; PAULO, Fernanda dos Santos. A formação de educadores na educação não formal pública. Revista Educ. Soc., Campinas, v. 35, n. 127, p. 551 -566, abr./jun. 2014. Disponível em: http://www.cedes.unicamp.br. Acesso em: 11 jul. 2015. 


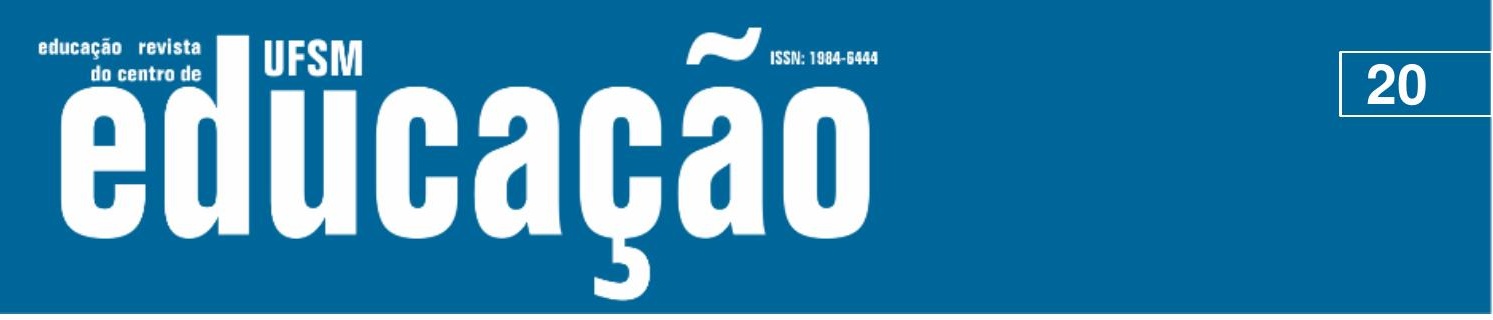

ISSN: 1984-6444 | http://dx.doi.org/10.5902/1984644447075

GARCIA, Valéria Aroeira. O papel da questão social e da educação não formal nas discussões e ações educacionais. Americana: UNISAL, 2008. Disponível em: http://unisal.br/wp-content/uploads/2013/09/mesa_8_texto_valeria.pdf. Acesso em: 30 de mar. 2020.

GOHN, Maria da Glória. Educação não formal: direitos e aprendizagens dos cidadãos(ãs) em tempos do coronavírus. Revista Humanidades e Inovação. v.7, n.7.7 - 2020. Disponível em: https://revista.unitins.br/index.php/humanidadeseinovacao/article/view/3259 Acesso em 20 de fevereiro de 2021.

GOHN, Maria da Glória. Educação não formal nas instituições Sociais. Revista Pedagógica, Chapecó, v. 18, n. 39, p. 59-75, set./dez. 2016. DOl: http://dx.doi.org/10.22196/rp.v18i39.3615. Acesso em 23 de mar. 2020.

GOHN, Maria da Glória. Educação não formal e o educador social. Atuação no desenvolvimento de projetos sociais. São Paulo: Cortez, 2010.

LÜDKE, Menga; ANDRÉ, Marli Eliza Dalmazo Alfonso de. Pesquisa em educação: abordagens qualitativas. São Paulo: EPU, 1986.

MÜLLER, Verônica Regina et all . A formação do profissional da educação social: espectros da realidade . In XVIII Seminário Internacional de Formação de Professores para o MERCOSUL/CONE SUL De 03 a 05 de novembro de 2010 Universidade Federal de Santa Catarina - UFSC. Florianópolis - Santa Catarina - Brasil. Disponível em $\quad: \quad$ https://seminarioformprof.ufsc.br/files/2010/12/M\%C3\%9CLLERVer\%C3\%B4nica-Regina3.pdf. Acesso em 22 de março de 2021.

MÜLLER, Veronica Regina; BAULI, Regis Alan. Normatização da profissão do(a) Educador(a)Social: mitos e metas. Ensino \& Pesquisa, [S.I.], jul. 2017. ISSN 2359$4381 . \quad$ Disponível em: http://periodicos.unespar.edu.br/index.php/ensinoepesquisa/article/view/1768.

Acesso em: 22 Mar. 2021. doi:http://dx.doi.org/10.33871/e\&p.v15i2.1768. Acesso em 22 de março de 2021.

NETO, João Clemente de Souza. O compromisso ético do educador social. Revista Lusófona de Educação, 2012, n. 22, p. 55-67.

PASSERI, Maria Eloisa Ferreira. SOCIAL EDUCATOR: CONSTRUCTION OF APPLIED TO KNOW SOCIAL POLICIES FOR CHILDHOOD AND ADOLESCENCE, $141 \mathrm{f}$. Dissertation Master in Social Science, State University of Maringá.

SUPERVISOR: Geovânio Edervaldo Rossato. Maringá. 2012. 


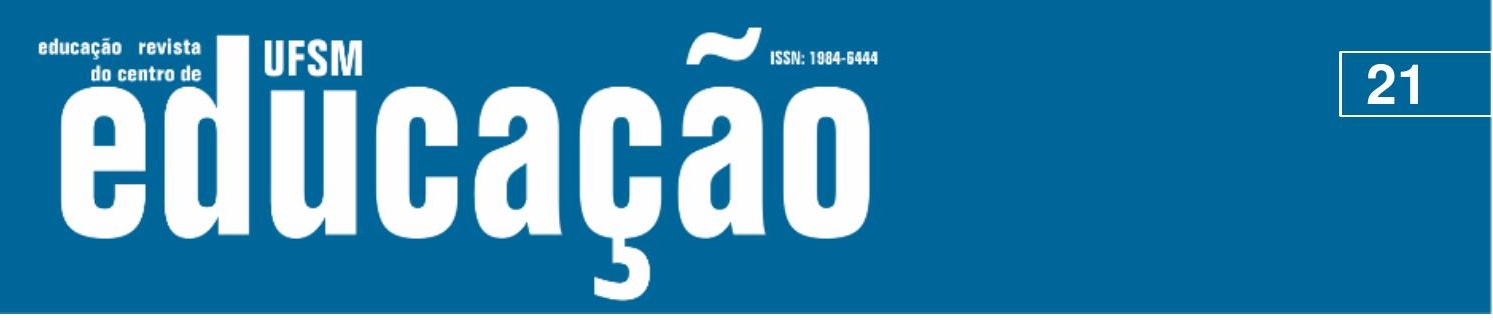

ISSN: 1984-6444 | http://dx.doi.org/10.5902/1984644447075

PERONI, Vera Maria Vidal. As relações entre o público e o privado nas políticas educacionais no contexto da terceira via. Currículo sem Fronteiras, v. 13, n. 2, p. 234-255, maio/ago. 2013 http://www.curriculosemfronteiras.org/vol13iss2articles/peroni.pdf Acesso em $10 \mathrm{de}$ abril de 2020.

PERONI, Vera Maria Vidal. Implicações da relação público-privada para a democratização da educação. Reunião Científica Regional da Anped. Educação, movimentos sociais e políticas governamentais. 24 a 27 de julho de 2016 . UFPR/Curitiba/Pr. Disponível em:

http://www.anpedsul2016.ufpr.br/portal/wp-

content/uploads/2015/11/Confer\%C3\%AAncia-de-Abertura-Vera-Peroni.pdf Acesso em 13 de março de 2021.

PERRUDE, Marleide Rodrigues da Silva; SILVA, Ana Lucia Ferreira da. Atuação do pedagogo em espaços não formais: algumas reflexões. Pro-docência. Revista Eletrônica das Licenciaturas/UEL, Londrina, v. 1, n. 4, jul./dez. 2013. ISSN 23180013. Disponível em: http://www.uel.br/revistas/prodocenciafope. Acesso em: 30 de março de 2020.

PEREIRA, Antonio. A formação inicial de educadores sociais no contexto dos cursos tecnológicos e de pedagogia: primeiras aproximações de um debate. Ensino \& Pesquisa, [S.I.], jul. 2017. ISSN 2359-4381. Disponível em: http://periodicos.unespar.edu.br/index.php/ensinoepesquisa/article/view/1773/1098.

Acesso em: 22 Mar. 2021. doi:http://dx.doi.org/10.33871/e\&p.v15i2.1773. Acesso em 22 de março de 2021.

RUMMERT, Sonia Maria. Formação continuada dos educadores de jovens e adultos: desafios e perspectivas. In: SOARES, Leôncio. Formação de educadores de jovens e adultos. Belo Horizonte: Autêntica SECAD/ME, 2006.

SÁ, Ricardo Antunes. Pedagogia: identidade e formação. O trabalho pedagógico nos Processos Educativos Não-Escolares. Educar em Revista, Curitiba, n. 16, p. 171180. 2000. Editora da UFPR. https://doi.org/10.1590/0104-4060.213. Acesso em 12 de abril de 2010.

SILVA, Gerson Heidrich da. Educador social: uma identidade a caminho da profissionalização ?. Educ. Pesqui. [conectados]. 2009, vol.35, n.3 [citado em 2021 03-22], pp.479-493. Disponível em: http://www.scielo.br/scielo.php?script=sci_arttext\&pid=S1517-

97022009000300005\&lng=en\&nrm=iso. ISSN

1678-4634. https://doi.org/10.1590/S1517-97022009000300005. Acesso em 22 de março de 2021 . 
